\title{
Determination of the Antibiotic Susceptibility Pattern of Clinical Isolates of Staphylococcus aureus Collected from Various Diagnostic Centers of Dhaka City, Bangladesh
}

\author{
Ehsan Al-din Siam ${ }^{1}$, Syeda Nuzhat Hoque ${ }^{2}$, Tasnim Jabin ${ }^{3}$, Md Ifrat Hossain ${ }^{4}$, \\ Muhammad Asaduzzaman', Md. Aftab Uddin' \\ Student, Department of Microbiology, Stamford University Bangladesh, Dhaka, Bangladesh ${ }^{1-4}$ \\ Lecturer, Department of Microbiology, Stamford University Bangladesh, Dhaka, Bangladesh ${ }^{5}$ \\ Assistant Professor, Department of Microbiology, Stamford University Bangladesh, Dhaka, Bangladesh ${ }^{6}$
}

\begin{abstract}
Staphylococcus aureus is one of the leading etiological agents of causing severe skin infections including bacteremia, cellulitis, and different kind of infections. This study was performed to check the drug susceptibility patterns of the phenotypically characterized S. aureus isolates collected from some popular diagnostic centers of Dhaka city. A total of 175 non-duplicate isolates were collected from various patients having different age groups and gender. The microorganisms obtained from diverse specimens (i.e. blood, urine, pus, sputum, ear, breast, nipple, catheter, tracheal aspirate) were identified by several phenotypic and biochemical tests. Antibiotic resistance patterns for 22 different antibiotics were evaluated by the Agar-disc-diffusion method to understand antibiotic susceptibility of the isolates. Out of 175 , a total of 110 samples were identified as $S$. aureus isolates. The female patients (58\%) were likely to be more susceptible to staphylococcal infection than their male counterparts (42\%). Of the 110 isolates, most of them were identified as Multi-Drug Resistant (MDR). The highest resistance was recorded against Cefixime (100\%), Azithromycin (83.7\%), Ciprofloxacin (71\%), Levofloxacin (63.6\%), and Ceftriaxone (61.8\%). Resistance levels of S. aureus against other antibiotics were also worrisome. This study highlighted the need for frequent surveillance of antimicrobial susceptibility patterns of Staphylococcus aureus with a view of selecting accurate antibiotic therapy in order to avoid the development of drug resistance. However, molecular studies are recommended for developing our current findings.
\end{abstract}

Keywords: Staphylococcus aureus, Skin infections, Multidrug-resistant, Therapy.

\section{INTRODUCTION}

Staphylococcus aureus is a gram-positive cocci shaped bacterium which is a member of the Staphylococcaceae family and natural human flora, present on the mucous membrane and skin surface and upper respiratory tract [1]. It also causes severe infections such as inflammations of bones, meninges, rashes, and septicemia by penetrating the internal tissues or bloodstream [2-3] as well as various kinds of toxin-mediated diseases such as gastroenteritis, staphylococcal scalded skin syndrome, and toxic shock syndrome. Staphylococcus aureus remains an important and frequent cause of morbidity and mortality in tropical countries [4]. S. aureus produces various pathogenic factors enabling colonization, adherence, and invasion of the mammary cells of bovine host cells to stimulate intramammary infections. Increased staphylococcal nasal colonization has been reported in insulin-dependent diabetes [5] hemodialysis [6] intravenous drug user [7], patients with symptomatic human immunodeficiency virus infection [8]. Staphylococcus aureus can also enter into the body via different kinds of food sources. Staphylococcal Food Poisoning (SFP) is a common foodborne disease globally resulting from different kinds of food consumption containing Staphylococcal Enterotoxin (SE) [9-10]. Symptoms and rapidity of onset (2-8 h) include nausea, vomiting, abdominal cramping with or without diarrhea [11]. Contamination is usually occurred by improper handling of processed food or cooked food, storage conditions allowing the growth of $S$. aureus. It is also a common cause of bovine mastitis and therefore, raw milk sometimes contaminated with S. aureus [12]. A total of 386-food borne outbreaks caused by staphylococcal toxins in the European Union according to the recent European Food Safety Authority Report [13].

Staphylococcus aureus has an anomalous ability to acquire resistance against to any antibiotic. Extensive and unplanned use of antibiotics in human and veterinary medicine is the key reason for the emerging of resistant strains of $S$. aureus [14]. Most of the clinically important antibiotic resistance is associated with the transfer of small pieces of extrachromosomal DNA. The mechanisms of resistance are numerous including a large number of plasmid mediate 
Vol. 7, Issue 6, June 2020

enzymatic resistance by drug inactivation, antibiotic trapping, efflux pumps, etc [15-16]. The generally used antibiotics for the cure of infections caused by $S$. aureus were $\beta$-lactam antibiotics including methicillin. Based on resistance development, Staphylococcus aureus can be categorized into two types; Methicillin-Resistant Staphylococcus Aureus (MRSA) and Methicillin Susceptible Staphylococcus Aureus (MSSA) [17]. A small number of Staphylococcal plasmids are known to have the gene for linked antibiotic resistance such as penicillin and fusidic acid, penicillin and erythromycin, penicillin and tetracycline, or neomycin and bacitracin and erythromycin. The most predominant method of penicillin resistance in Staphylococcus aureus is the production of penicillinase which destroys the ß-lactam ring of penicillin. Intercell contact may be necessary for the transfer of plasmids among cells. So this occurs most often in patients with an infected skin lesion.

The current study provides information regarding the phenotypic characterization of Staphylococcus aureus along with the antibiotic susceptibility pattern in the clinically suspected cases of staphylococcal infection from a diverse specimen of various patients.

\section{MATERIALS AND METHODS}

\section{Collection of samples}

The samples were collected between the periods of November 2019 to February 2020. The samples were collected from two diagnostic centers of Dhanmondi and Badda area of Dhaka city, Bangladesh. A total of 175 non-duplicate $S$. aureus isolates were found from blood, urine, pus, sputum, ear, breast, nipple, umbilical, drain tube, catheter, nasal, and tracheal aspirate collected from human patients of different age and gender with different diseases. Sample processing and transportation were maintained as per WHO guidelines [18]. All experiment was performed in the Department of Microbiology, Stamford University Bangladesh.

\section{Isolation and confirmation of Staphylococcus aureus}

Pure-culture of $S$. aureus was isolated and maintained using Mannitol salt aga (MSA). All the strains were collected aseptically and transferred into Mannitol Salt Agar media. The collected samples were incubated overnight at $37^{\circ} \mathrm{C}$ for 24 hours and 60 samples were selected for further analysis.

\section{Microscopic analysis}

Microscopic analysis of the isolates was done through bacterial size, shape, and staining properties [19]. Initial identification of selected isolates were performed by gram staining procedure, followed by different biochemical test. Cultural and morphological characteristics of selected isolates were identified according to standard microbiological protocols [20].

\section{Biochemical test for the confirmative identification}

All isolated bacteria were identified by standard laboratory biochemical tests according to the methods described elsewhere (21). The biochemical tests for $S$. aureus were indole test, MR-VP test, catalase test, oxidase test, urease test, beta hemolysis test, coagulase test, citrate utilization test, $\mathrm{H}_{2} \mathrm{~S}$ production test as well as mannitol fermentation test [20$22]$.

\section{Determination of antimicrobial susceptibility by disk diffusion method}

Pure culture of $S$. aureus isolated from different clinical samples was selected for assaying antimicrobial susceptibility pattern against a different group of antibiotics such as Amikacin (30 $\mu \mathrm{g})$, Amoxyclav (30 $\mu \mathrm{g})$, Azithromycin (30 $\mu \mathrm{g})$. Cefixime $(5 \mu \mathrm{g})$, Ceftriaxone $(30 \mu \mathrm{g})$, Cefuroxime $(30 \mu \mathrm{g})$, Cephradine $(30 \mu \mathrm{g})$, Ciprofloxacin $(5 \mu \mathrm{g})$, Cloxacillin $(30 \mu \mathrm{g})$, Cotrimoxazole $(30 \mu \mathrm{g})$, Doxycycline $(30 \mu \mathrm{g})$, Erythromycin $(30 \mu \mathrm{g})$, Fusidic acid $(30 \mu \mathrm{g})$, Gentamycin $(30 \mu \mathrm{g})$, Meropenem $(30 \mu \mathrm{g})$, Teicoplanin $(30 \mu \mathrm{g})$, Tetracycline $(30 \mu \mathrm{g})$, Vancomycin $(30 \mu \mathrm{g})$, Linezolid $(30 \mu \mathrm{g})$, Tigecycline $(30 \mu \mathrm{g})$, Clindamycin $(30 \mu \mathrm{g})$ and Levofloxacin $(30 \mu \mathrm{g})$ by Kirby Bauer disc diffusion method [23] as recommended by clinical and Laboratory Standards Institute (CLSI) guideline 2013.

\section{RESULTS}

In this study, all suspected plates were examined for the presence of $S$. aureus yellow colors on MSA media. All suspected S. aureus isolates were confirmed by gram staining microscopic analysis and biochemical tests. Among those 175 samples, 134 strains were isolated from MSA selective media, and 109 of them were identified as $S$. aureus isolates by performing different biochemical tests. Table 1 shows the biochemical test results of all suspected $S$. aureus isolates. 
Vol. 7, Issue 6, June 2020

Table 1: Biochemical tests for the isolates bacteria

\begin{tabular}{l|c|c|c|c|c|c|c|c|c|c|c}
\hline $\begin{array}{l}\text { Assumed } \\
\text { Organism }\end{array}$ & $\begin{array}{c}\text { Coagulase } \\
\text { Test }\end{array}$ & $\begin{array}{c}\text { H2S } \\
\text { production }\end{array}$ & $\begin{array}{c}\text { Indole } \\
\text { Test }\end{array}$ & $\begin{array}{c}\text { MR } \\
\text { Test }\end{array}$ & $\begin{array}{c}\text { VP } \\
\text { Test }\end{array}$ & $\begin{array}{c}\text { Citrate } \\
\text { Test }\end{array}$ & $\begin{array}{c}\text { Tosidase } \\
\text { Test }\end{array}$ & $\begin{array}{c}\text { Catalase } \\
\text { Test }\end{array}$ & $\begin{array}{c}\text { rrease } \\
\text { Test }\end{array}$ & $\begin{array}{c}\text { Mannitol } \\
\text { Fermenta } \\
\text { tion Test }\end{array}$ & $\begin{array}{c}\text { Nitrate } \\
\text { Reduction } \\
\text { Test }\end{array}$ \\
S. aureus & + & - & - & + & + & - & - & + & + & + & + \\
\hline
\end{tabular}

$\mathrm{MR}=$ Methyl red, VP =Voges-Proskauer,

In this study, a total of 109 isolates were suspected to be suffering from S. aureus infections of male and female gender with different ages from 1 to 100 [Figure 1(a)]. We found that female patients are likely to be more susceptible to Staphylococcal infection than male patients. Among the isolates tested 58\% of them were obtained from female patients and about $42 \%$ were obtained from male patients [Figure 1(b)].

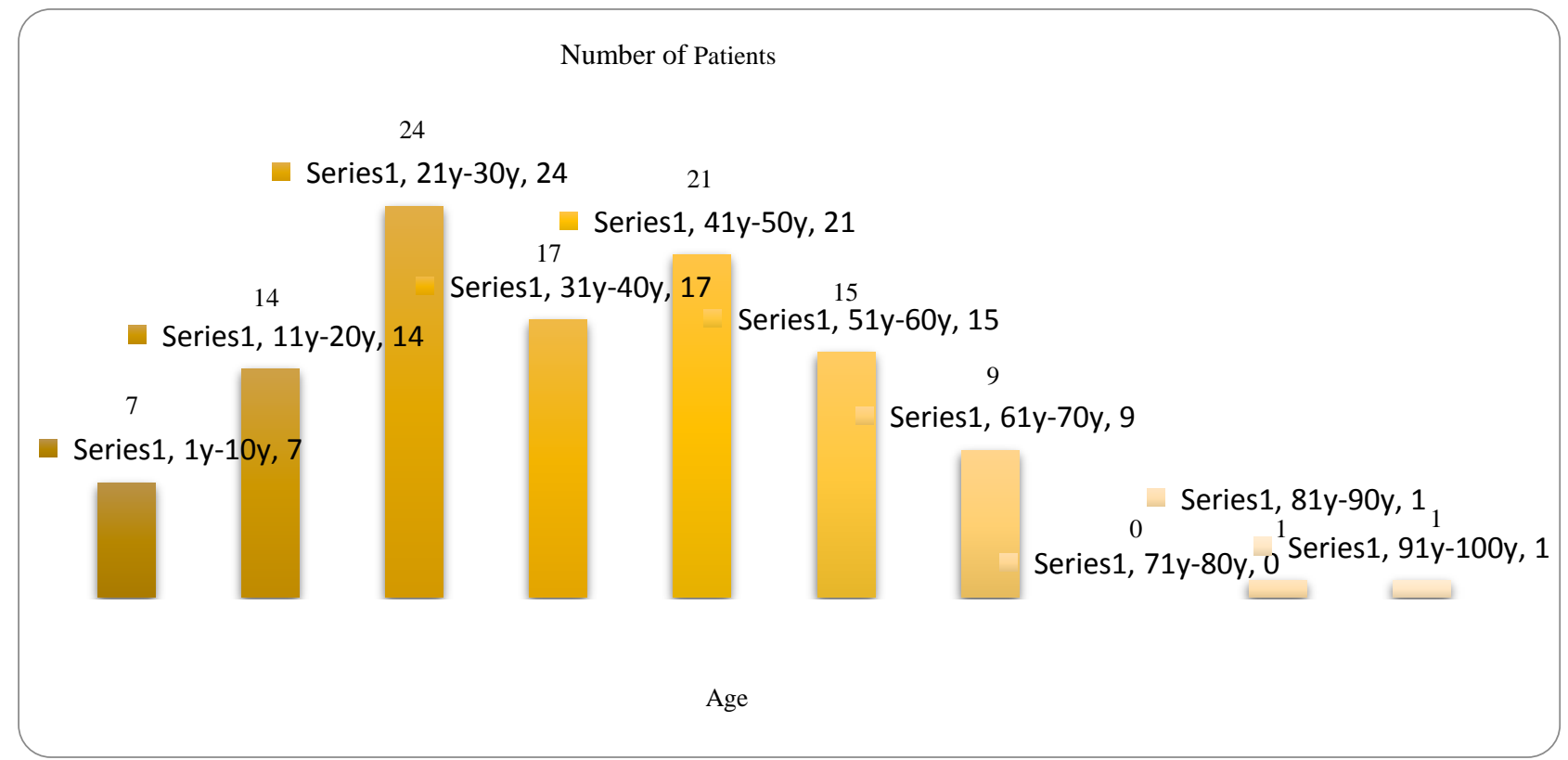

Figure 1(a): Distribution of age groups among respondents

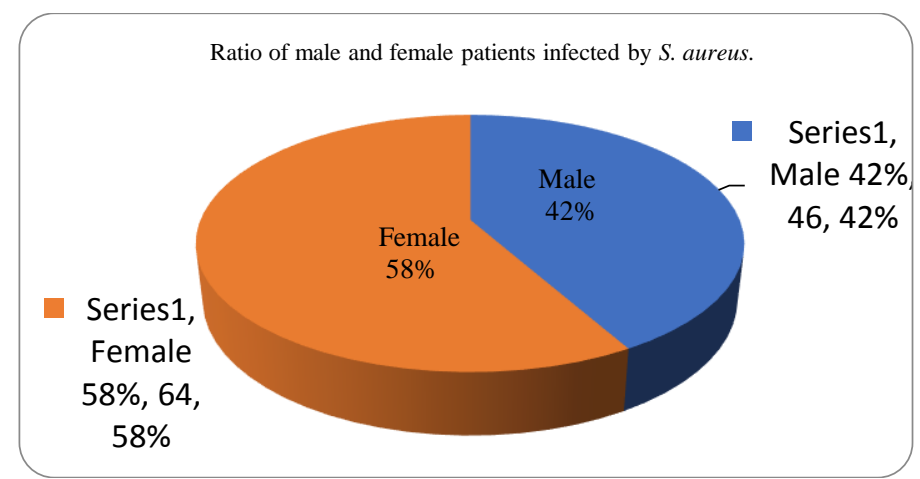

Figure 1(b): Distribution of gender groups among respondents

The rate of infection seems to vary randomly according to age without any selective pattern, although, the tendency of getting affected by different staphylococcal infections seem to be higher in between the ages from 21-50 years old whereas the lowest prevalence rate was observed between the age group from 71-100 years old according to the present study findings.

One hundred and ten clinical isolates of $S$. aureus were subjected to antimicrobial resistance test against different commercial antibiotics. With the $100 \%$ resistance of cefixime demonstrated as the most resistant antimicrobial followed by Azithromycin (83.7\%), Ciprofloxacin (71\%), Levofloxacin (63.6\%), Ceftriaxone (61.8\%), Cloxacillin (34.5\%), \%), Cotrimoxazole (33.6\%), Cephradine (31\%), Clindamycin (29.1\%), Clindamycin (29.1\%), Cefuroxime (27.3\%), 


\section{International Advanced Research Journal in Science, Engineering and Technology}

Vol. 7, Issue 6, June 2020

Meropenem (23.6\%), Gentamycin (22.7\%), Fusidic Acid (21.8\%), Amoxyclav (19.1\%), Amikacin (9.1\%), Tigecycline (3.6\%), Linezolid $(2.7 \%)$. However, Teicoplanin $(0 \%)$, Vancomycin $(0 \%)$ was found to be the most effective drug as all the studied isolates were proved to be sensitive against this antibiotic [Figure 2].

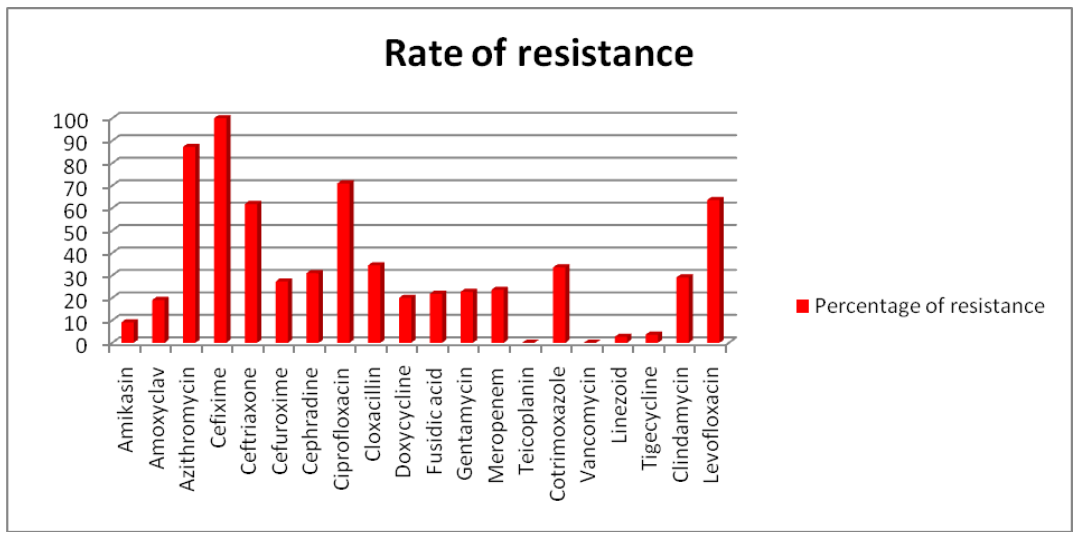

Figure 2: Antibiotic resistance pattern of $S$. aureus isolates $(\mathrm{n}=110)$

In our present study, 85 strains (77\%) were found to be multidrug-resistant among 109 Staphylococcus aureus isolates. Table 2 shows the various sources of specimen for the isolation of Staphylococcus aureus and antibiotic resistance pattern of different isolates to various antibiotics among age groups and sex. The highest frequency of resistance was from (6170) years old in case of male patients $16(80 \%)$ and observed with Pus, Right ear and Wound swab infections while the least resistance was in the (81-90) years old in case of male $3(15 \%) \&$ female patients $4(20 \%)$ and observed with Urine infections. Interestingly, all antibiotics were proved to be effective for the age group (71-80) years old and (91-100) years old patients.

\begin{tabular}{|c|c|c|c|}
\hline $\begin{array}{l}\text { Age group } \\
\text { (Years) }\end{array}$ & Sex & Specimen type & $\begin{array}{c}\text { Number of antibiotics } \\
\text { and percentage of } \\
\text { resistance }\end{array}$ \\
\hline \multirow[b]{2}{*}{$1-10$} & $\mathrm{M}$ & Umbilical swab & $13(65 \%)$ \\
\hline & $\mathrm{F}$ & Blood, Pus & $12(60 \%)$ \\
\hline \multirow{2}{*}{$11-20$} & $\mathrm{M}$ & Pus & $5(25 \%)$ \\
\hline & $\mathrm{F}$ & Urine, Blood, Wound swab, Right ear & $9(45 \%)$ \\
\hline \multirow{2}{*}{$21-30$} & $\mathrm{M}$ & Right ear, Catheter tip, Pus, Nasal swab & $10(50 \%)$ \\
\hline & $\mathrm{F}$ & Urine, Nipple, Wound swab & $10(50 \%)$ \\
\hline \multirow{2}{*}{$31-40$} & $\mathrm{M}$ & Blood, Pus & $9(45 \%)$ \\
\hline & $\mathrm{F}$ & Urine, Breast, Pus, Wound swab & $11(55 \%)$ \\
\hline \multirow{2}{*}{$41-50$} & $\mathrm{M}$ & Pus, Wound & $14(70 \%)$ \\
\hline & $\mathrm{F}$ & Tracheal Aspirate, Blood, Pus, left ear, Catheter tip, Wound swab & $13(65 \%)$ \\
\hline \multirow{2}{*}{$51-60$} & $\mathrm{M}$ & Urine, Wound swab & $15(75 \%)$ \\
\hline & $\mathrm{F}$ & Blood, Drain tube & $11(55 \%)$ \\
\hline \multirow{2}{*}{$61-70$} & $\mathrm{M}$ & Pus, Right ear, Wound swab & $16(80 \%)$ \\
\hline & $\mathrm{F}$ & Blood, Blood catheter, Pus & $11(55 \%)$ \\
\hline \multirow{2}{*}{$71-80$} & M & - & - \\
\hline & $\mathrm{F}$ & - & - \\
\hline \multirow{2}{*}{$81-90$} & M & Urine & $3(15 \%)$ \\
\hline & $\mathrm{F}$ & Urine & $4(20 \%)$ \\
\hline \multirow{2}{*}{$91-100$} & $\mathrm{M}$ & - & - \\
\hline & $\mathrm{F}$ & - & - \\
\hline
\end{tabular}

\section{DISCUSSION}

In our present study, female patients were more affected (58\%) than male patients (48\%). Although a staphylococcal infection can occur at any age, in our present study, the patient's age ranged from 21-30 years were more affected in terms of male and female patients whereas the lowest incidence rate of infection was in between 81-100 years of age. 


\title{
International Advanced Research Journal in Science, Engineering and Technology
}

\author{
Vol. 7, Issue 6, June 2020
}

The patient's age ranged from 21-30 years showed the highest degree of susceptibility pattern [24] for the staphylococcal infection followed by 41-50 years (21), 31-40 years (17), 51-60 years (15), 11-20 years (14). Although, no infected patients were found in the age ranged from 71 to 80 years after investigating 110 clinically suspected patients.

Staphylococcus aureus develops resistance very quickly to different antibiotics over a period of time. Due to the reckless and widespread use of antibiotics, the resistance profile of microorganisms is changing gradually, especially in developing countries [24-25]. In our study, antibiotic resistance pattern revealed that among the isolates, $100 \%$ isolates showed resistance against Cefixime, followed by Azithromycin (83.7\%), Ciprofloxacin (71\%); intermediate level of resistance was showed in case of Levofloxacin (63.6\%), Ceftriaxone (61.8\%). The least level of resistance was found against Tigecycline (3.6\%), Linezolid (2.7\%). In our present study, Vancomycin ( $0 \%)$ was found to be the most effective drug, this outcome is in similar with the findings of Hizbullah et al. (2015) [26]; Shah et al. (2016) [27]; Ullah et al. (2016) [28]. All of these studies had reported $0 \%$ resistance against vancomycin. However, resistance against Ciprofloxacin and Gentamycin was estimated as $71 \%$ and $22 \%$ respectively which is almost similar to a recent study [29] where Ciprofloxacin and Gentamycin were encountered as $77 \%$ and $13.21 \%$ respectively. The frequency of antimicrobial resistance was observed with different ages and gender in terms of different specimen types. The highest frequency of resistance was from (61-70) years old male patients 16 (80\%). However, non- resistance antibiotic was found in the age between (71-80) years and (91-100) years old patients.

The susceptibility pattern of antimicrobials against Staphylococcus aureus has given us an outline of the uncontrolled use of antibiotics through this study. The judicious use of antibiotics by the experts such as doctors or health professionals and effort to control misuse of antibiotics and procurement will assist in limiting the increasing rate of antibiotic resistance in the pathogenic microorganisms. Inappropriate prescribing of antibiotics for viral infections, against which they have no effect or antibiotic use for these conditions are unnecessary. Rational drug policy should be in use before addressing the potent antibiotics to the country [30]. Antibiotic administration should follow certain minimal requirements [31].

In Bangladesh, it is necessary to carry out a constant assessment of antibiotic susceptibility patterns of resistant pathogenic microorganisms for commonly used antimicrobial agents in a particular environment. The present situation of antimicrobial resistance in Bangladesh should be taken into account seriously, otherwise, it will become an uncontrollable problem not only in Bangladesh but also worldwide in the near future.

\section{CONCLUSION}

Staphylococcus aureus remains a worldwide cause of infection of skin as well as causing life-threatening diseases such as pneumonia, meningitis, osteomyelitis, endocarditis, toxic shock syndrome, bacteremia, and sepsis specially on developing and underdeveloped countries like Bangladesh [32]. In conclusion, our study emphasizes the development of public awareness regarding the prevention and spread of staphylococcal infection. The best way to prevent the spread of $S$. aureus in hospital settings is to screen health caretakers for the presence of these organisms. Continuous monitoring of the antimicrobial susceptibility pattern of S. aureus isolates for the selection of appropriate therapy is also very much required. However, further molecular studies are recommended to study and monitor the epidemiology of multiple drugresistant $S$. aureus.

\section{ACKNOWLEDGMENT}

We express great thanks and sincere appreciation to the Department of Microbiology, Stamford University, Bangladesh for logistic support throughout our study.

\section{REFERENCES}

[1]. M.Z. Zaher, Investigation of the ability of some commensal members of the nasal and/or skin microbiota to inhibit or eliminate multidrug-resistant Staphylococcus aureus. CU Theses, 2019.

[2]. T.A. Taylor and C.G. Unakal, Staphylococcus aureus. Stat Pearls, Treasure Island (FL): StatPearls Publishing, 2019.

[3]. L.M. Weiner, A.K. Webb, B. Limbago, M.A. Dudeck, J. Patel, A.J. Kallen, J. R. Edwards and D.M. Sievert, Antimicrobial-resistant pathogens associated with healthcare-associated infections: Summary of data reported to the national healthcare safety network at the centers for disease control and prevention. Inf. Cont. Hosp. Epidemiol, 37(11):1288-1301, 2016.

[4]. B.A. Onile and T.O. Odugbemi, C. Nwofor, Antibiotic susceptibility of Bacterial agents of Septicemia in Ilorin. Nig Med Pract, 9(4):16-18, 1985.

[5]. C.U. Tuazon, A. Perez, T. Kishaba and J.N. Sheagren, Staphylococcus aureus among Insulin Injecting diabetic patients: An increased carrier rate. JAMA, 231(12):1272, 1975.

[6]. V.L. Yu, A. Goetz and M. Wagener, Staphylococcus aureus Nasal carriage and infection in patients on haemodialysis: Efficacy of antibiotic prophylaxis. New Engl J Med, 315:91-96, 1986.

[7]. C.V. Tuazon and J.N. Sheagren, Increased rate of carriage of Staphylococcus aureus among narcotics addicts. J Infect Dis, $129(725), 1974$.

[8]. M. C. Raviglone, P. Marvius, A, Pabloz-Mendel, R. Battan, P. Ottuso and A. Taranta. High Staphylococcus aureus nasal carriage rate in patients with acquired immunodeficiency syndrome (AIDS) related complex. Am J Infect Control, 18:64-69, 1990.

[9]. G. Normanno, M. Corrente, G. La Salandra, A. N.C. Dambrosio, N.C. Quaglia, A. Parisi, G. Greco, A.L. Bellacicco, S. Virgilio and G.V Celano, Methicillin-resistant Staphylococcus aureus (MRSA) in foods of animal origin product in Italy. Int. J. Food Microbiol, 117:219-22, 2007.

[10]. S. Loncarevic, H.J. Jørgensen, A. Løvseth, T. Mathisen and L.M. Rørvik, Diversity of Staphylococcus aureus enterotoxin types within single samples of raw milk and raw milk products. J. Appl. Microbiol, 98:344-50, 2005. 


\section{International Advanced Research Journal in Science, Engineering and Technology}

Vol. 7, Issue 6, June 2020

[11]. Y. Le Loir and F. Baron, Gautier M. Staphylococcus aureus and food poisoning.Genet. Mol. Res, 2:63-76, 2003.

[12].EC-European Commission Opinion on Staphylococcal Enterotoxins in milk products, particularly cheeses 2003; Available online: http://ec.europa.eu/food/fs/sc/scv/out61_en.pdf.

[13]. EFSA and ECDC (European Food Safety Authority and European Centre for Disease Prevention and Control) The European Union summary report on trends and sources of zoonoses, zoonotic agents and food-borne outbreaks in 2013. EFSA J, 13:3991, 2015

[14]. H.A. Grema, Y.A. Geidam and G.B. Gadzama, J.A, Ameh and Suleiman. Methicillin resistant Staphylococcus aureus (MRSA): a review. Adv. Anim, Vet. Sci, 3(2):79-98, 2015

[15]. R. Benveniste and D. Julian, Mechanisms of antibiotic resistance in bacteria. Annu. Rev. Biochem, 42(1):471-506, 1973.

[16]. R.J. Piso, R. Käch, R. Pop, D. Zillig, Schibli U, Bassetti S, U. Schibli, S. Bassetti, D.M. Meinel and A. Egli, A cross-sectional study of colonization rates with methicillin-resistant Staphylococcus aureus (MRSA) and extended-spectrum beta-lactamase (ESBL) and carbapenemase-producing Enterobacteriaceae in four Swiss refugee centers. PLoS One, 12(1): e0170251, 2017.

[17]. Gurusami, R. Koti, C.D. Toon, P. Wilson, B.R, Davidson. Antibiotic therapy for the treatment of methicillin-resistant Staphylococcus aureus (MRSA) infections in surgical wounds. T. Coch. Data. Sys. Rev, (8): CD009726, 2013.

[18]. Guidance on regulations for the transport of infectious substances, World Health Organization, USA $2009-10$.

[19]. N.R. Kreig, J.G. Holt and D.H. Bergey, Bergeys Manual of Systematic Bacteriology. 1st ed. East Preston street, Baltimore, 1984.

[20]. J.G. Collee, B.P. Marmion and A.G. Fraser, Practical Medical Microbiology. 14th ed. Churchill Livingstone, New York, 1996.

[21]. Collee J.G, Miles R.S and Watt B. Tests for identification of bacteria. In Mackie and McCartneyPractical Medical Microbiology. 14th edition, JG. Collee, AG.Fraser, BP Marmion, A Simmons (Eds.), pp.131-49,166-7. Churchill Livingstone: New York, 1996.

[22]. W.C.Winn, Koneman's Color Atlas and Textbook of Diagnostic Microbiology.14th ed. Lippincott Williams \& Wilkins, 1996.

[23]. A.W. Bauer, W.M. Kirby, J.C, Sherris and M Turck. Antibiotic susceptibility testing by a standardized single disk method. Ameri. J. Clin. Pathol, 45(4): 493-496, 1966.

[24]. T.F. O'Brien, Resistance to antibiotics at medical centers in different parts of the world. J Antimicrob Chemother, 18: 919-926, 1986.

[25]. A. Lamikanra and RB Ndap, Trimethoprim resistance in urinary tract pathogens in two Nigerian hospitals. J Antimiuob Chemother, 23(1):151$154,1989$.

[26]. Hizbullah, A. Fahad, B. Sulaiman, S . Zunaira, Rahimullah, A.K. Muhammad, K. Rahman, A. Ahmad, A. Aziz, M. Daud, I. Khan, J. Khan, A. Hayat, M. Rahman and M.A. Khan, Antibiotic Susceptibility Patterns of Methicillin-Resistant Staphylococcus aureus at National Institute of Health Sciences, Islamabad, Pakistan. W. J. of Zool, 10(4): 318-322, 2015.

[27]. F.A. Shah, S.U. Din and WAWM Khan, Frequency and antimicrobial susceptibility pattern of Methicillin-resistant Staphylococcus aureus in open fractures. J. of Surg. Pak, 21(2): 62-66, 2016.

[28]. A. Ullah, M. Qasim, H. Rahman, J. Khan, M. Haroon, N. Muhammad, K. Abdullah and N. Muhammad, High frequency of methicillin-resistant Staphylococcus aureus in Peshawar region of Pakistan. Springer Plus, 5(1): 600, 2016.

[29]. N.E. Onwubiko and M.S. Nasiry, Antibiotic sensitivity pattern of Staphylococcus aureus from clinical isolates in a tertiary health institution in Kano, Northwestern Nigeria. Pan Afr Med J., 8: 4, 2011.

[30]. A. Aseffa and G. Yohhannes, Antibiotic Sensitivity of Staphylococcus Aureus and Escherichia Coli Strains Isolated in Gondar, Ethiopia. 15: 27(2):121-2, 1997.

[31]. E.M.H.Wellington and J. D Van Elsas, Genetic interactions among microorganisms in the natural environment; Pergamon press, Oxford. $1^{\text {st }}$ ed. Pergamon publisher, 1992

[32]. A.Voss and B. N. Doebbeling, The worldwide prevalence of methicillin-resistant Staphylococcus aureus. International journal of antimicrobial agents., 5(2): 101-106, 1995. 